\title{
Ampliando horizontes: ensino de inglês para crianças com transtorno do espectro autista
}

\author{
Otto Henrique Silva Ferreira" \\ Juliana Reichert Assunção Tonelli"*
}

\section{Resumo}

Quando tratamos do ensino de inglês para crianças, o cenário da educação atual se apresenta como propício a propostas de pesquisas que fortaleçam a importância da inclusão em contexto escolar. Neste trabalho objetivamos discutir, por meio de análise qualitativo-interpretativa, o papel da aprendizagem da língua inglesa para crianças com transtorno do espectro autista (TEA) em seu desenvolvimento linguístico, evidenciando a contribuição da língua inglesa para a superação das dificuldades de aprendizagem que podem surgir em decorrência do diagnóstico. Os dados foram gerados a partir de atividades inseridas em uma sequência didática desenvolvida e aplicada em contexto de estágio supervisionado em língua inglesa, junto a uma turma do nível pré-5, incluindo um aluno autista. Os resultados apontam que, realizadas as adaptações de materiais e abordagens, o ensino da língua pode favorecer o desenvolvimento linguístico das crianças com TEA, além de possibilitar o engajamento social, a fim de caracterizar, de fato, a inclusão.

Palavras-chave: Ensino de inglês para crianças. Transtorno do espectro autista. Inclusão escolar. Desenvolvimento linguístico.

\section{Introdução}

A área de ensino de língua inglesa para crianças (LIC) como língua adicional vem crescendo em número de pesquisas, o que abre possibilidades para novos debates, e envolvem-se temáticas que agregam conhecimentos e auxiliam na formação de professores para atuarem também no contexto da educação infantil e primeiro ciclo do ensino fundamental (TONELLI; CRISTOVÃO, 2010; SANTOS, 2011; TUTIDA, 2016). Em contrapartida, a Base Nacional Curricular Comum (BRASIL, 2017), frustrando o desejo e as necessidades de educadores/

\footnotetext{
Mestrando do Programa de Pós-graduação em Estudos da Linguagem da Universidade Estadual de Londrina (UEL). E-mail: otto.letras@gmail.com

** Pós-doutora em Didática das Línguas pela Universidade de Genebra e em Linguística Aplicada pela Universidade de Brasília. Docente no Curso de Letras Estrangeiras do Departamento de Letras Estrangeiras Modernas da Universidade Estadual de Londrina (UEL). Docente permanente no Programa de Pós-graduação em Estudos da Linguagem e no Mestrado Profissional em Letras Estrangeiras Modernas (UEL). E-mail: jtonelli@uel.br
}

Data de submissão: set. 2020 - Data de aceite: nov. 2020 http://dx.doi.org/10.5335/rdes.v16i3.11449 
as que atuam nesta etapa da escolarização, não inclui o ensino de LIC nos anos iniciais, e apresenta uma proposta de ensino de língua inglesa baseada nas interações sociais e a aprendizagem por meio das práticas somente para alunos mais velhos.

Como consequência da aplicação da política de inclusão escolar advinda da Lei Brasileira de Inclusão (Lei $\mathrm{n}^{\circ}$ 13.146/2015), que garante a todos os alunos direitos iguais de receberem a educação e a informação, vem aumentando o número de alunos com laudo de deficiência nas escolas. Em virtude disso, é necessário que os professores estejam preparados para a possibilidade de trabalharem em contextos de inclusão, já considerando que cada um dos alunos em sala de aula possui suas singularidades e que há alunos que necessitam de adaptações de materiais e propostas, pois só por meio de capacitação os docentes saberão agir e transformar o ambiente escolar em inclusivo (VITALIANO, 2013).

Dentre os possíveis laudos, de acordo com Lemos, Nunes e Salomão (2020), o de transtorno do espectro autista (TEA) vem, cada vez mais, sendo identificado nas escolas. Os alunos com o diagnóstico de TEA têm as suas capacidades de socialização e interação afetadas (PENNINGTON, 1997), além da busca pelo reconhecimento de padrões e referências que lhes proporcionem segurança nos ambientes onde frequentam, incluindo a escola. Diante dessas e outras características que serão apresentadas em seção subsequente, entendemos que sejam necessárias atividades e propostas que contemplem as necessidades específicas desses alunos, sendo que é essencial que os professores tenham a formação adequada para lidarem com o preparo e a utilização desses materiais (ROCHA, 2016; MEDRADO; CELANI, 2017).

Neste artigo, discutimos por meio de análise de atividades componentes de uma sequência didática ${ }^{1}$ (SD) (DOLZ; NOVERRAZ; SCHNEUWLY, 2004), ancorada no referencial teórico relacionado ao TEA e ao ensino de LIC, possíveis contribuições que a aprendizagem de uma língua estrangeira/adicional, mais especificamente o inglês, pode promover ao desenvolvimento das capacidades de linguagem $^{2}$ (CL) (DOLZ; PASQUIER; BRONCKART, 1993) do aluno autista, tomando por base o interacionismo sociodiscursivo (BRONCKART, 2003), corrente teórica que considera a linguagem como elemento fundador do funcionamento e desenvolvimento humano. Acreditamos que por meio da linguagem a criança possa tornar-se apta a agir e interagir na sociedade, estabelecendo relações interpessoais e lidando com sujeitos e objetos.

O trabalho está organizado em cinco partes: na primeira, apresentamos a definição e as características do TEA, junto a um panorama das legislações 
e diretrizes vigentes no Brasil para o ensino e a inclusão. Após, fazemos uma relação com o campo do ensino e a aprendizagem de LIC, visando compreender como estes ocorrem atualmente em nosso país, de acordo com o aporte teórico que fundamenta este artigo. Em seguida, iniciamos a discussão para compreender se, e de que forma, ocorreu a inclusão de um aluno com TEA em grau severo (S1) em aulas de inglês e de que forma o ensino de inglês pode colaborar para o seu desenvolvimento linguístico. Na quarta parte, discorremos sobre os métodos e analisamos três atividades realizadas por S1 e, por fim, são apresentadas as considerações finais a respeito do tema discutido no artigo.

\section{O transtorno do espectro autista e inclusão}

O TEA, assim denominado após as modificações de nomenclatura trazidas pelo manual de diagnóstico e estatística de transtornos mentais ${ }^{3} 5$ (DSM-5) (APA, 2013), é definido por Pennington (1997) como um transtorno que pode implicar em dificuldades de aprendizagem diante do fato de afetar os indivíduos em suas capacidades de cognição social e interação; além disso, algumas crianças diagnosticadas com TEA desenvolvem a oralidade tardiamente, o que pode implicar na necessidade de adaptação de atividades para esses alunos.
Os desafios que envolvem a inclusão de crianças com TEA em sala de aula estão relacionados à construção de relações sociais e contextos que favoreçam o estabelecimento de ciclos de amizade e relacionamento afetivo junto a esses alunos, pois é importante que visualizem a escola como um ambiente acolhedor, a fim de aprenderem de forma significativa. De acordo com Pennington (1997), o diagnóstico precoce pode funcionar como uma ferramenta que facilita a definição de estratégias que favoreçam a aprendizagem e o desenvolvimento cognitivo da criança.

No Brasil, a Lei ํㅜำ 12.764 (BRASIL, 2012) instituiu uma política de proteção aos direitos dos indivíduos com TEA, reconhecendo essas pessoas perante as suas limitações e características comuns e reservando seus direitos como portadores de uma síndrome clínica.

Segundo Silveira, Santos e Silva (2015), os prejuízos em que o TEA implica podem limitar o interesse dos alunos em atividades escolares tradicionais, tornando ainda mais importante os processos de desenvolvimento e elaboração de materiais, além da escolha adequada pela abordagem a ser utilizada. Em adição, Rocha e Tonelli (2013b, p. 3) caracterizam o TEA como um transtorno que "priva o indivíduo de seu desenvolvimento social pleno".

Considerando as peculiaridades e individualidades apresentadas por cada uma das crianças presentes na sala de 
aula, podemos definir a escola como um ambiente heterogêneo, repleto de indivíduos que aprendem e se desenvolvem de formas únicas e diferentes (COUDRY; FREIRE, 2005). A Lei no 9.394 (BRASIL, 1996), aprovada após a Declaração de Salamanca (BRASIL, 1997), garante o ensino que contempla as características individuais de cada aluno, de modo a possibilitar a aprendizagem de todos.

Para obter a inclusão dos alunos com TEA em sala de aula, precisamos nos pautar do conceito de educação para todos (BRASIL, 1988) e compreendermos como passamos de um sistema que excluía os alunos com deficiência, para o sistema que busca incluí-los junto aos alunos regulares em sala de aula.

No passado, as pessoas com deficiência eram marginalizadas pela sociedade, o que se estendia também ao ambiente escolar, onde eram rejeitadas e forçadas a tentarem se adequar às condições, às propostas e normas consideradas padrões para a sociedade (CARNEIRO, 2012). Sanches e Teodoro (2006), por sua vez, abordam o movimento de passagem desse cenário de exclusão, em que os alunos com deficiência sofriam com as imposições, para o de inclusão, onde há propostas de adaptação de metodologias e materiais para o ensino desses alunos em salas regulares, considerando suas individualidades e necessidades, sem deixar de lado o fato de que eles são parte de um grupo em que todos devem ser ensinados.
A inclusão se tornou mais visível e ganhou força no cenário da educação brasileira a partir da sanção da Lei Brasileira de Inclusão (Lei no ${ }^{\circ}$ 13.146/2015) que, em seu texto, esclarece ter o objetivo de "assegurar e a promover, em condições de igualdade, o exercício dos direitos e das liberdades fundamentais por pessoa com deficiência, visando à sua inclusão social e cidadania" (BRASIL, 2015, art. $\left.1^{\circ}\right)$. Por considerarmos a escola como um local para a construção da identidade social do cidadão e o desenvolvimento por meio das interações, afirmamos que a lei deve ser contemplada dentro do ambiente escolar, a fim de favorecer o desenvolvimento do conhecimento dos alunos com deficiência no contexto de inclusão escolar.

Segundo Vitaliano (2013), os principais atores para a constituição de mudanças que transformam o ambiente escolar em acolhedor e inclusivo, são os professores e gestores escolares, por meio de ações que possibilitem e promovam a aprendizagem. Porém, a autora assume que há dificuldades relacionadas à implantação da educação inclusiva, destacando entre as possíveis razões para a existência de tais dificuldades a falta de investimento na área para a compra de materiais pedagógicos e ferramentas, adaptações estruturais para fins de acessibilidade nas escolas, além do despreparo dos profissionais que deveriam fazer a diferença na implementação das práticas 
inclusivas. Ainda, segundo a autora, isto ocorre, pois há lacunas na formação oferecida em cursos de licenciatura, que não preparam suficientemente os alunos para atuarem em contexto de inclusão.

Concordamos com Barros, Silva e Costa (2015) quando destacam o fato de que os esforços políticos e financeiros para a efetividade das propostas inclusivas devem ser vistos na prática e não somente em legislações e diretrizes. A luta pelos direitos básicos, como o de aprender, só se transforma, realmente, em conquista, quando há a possibilidade de ser concretizada na sociedade em situações e contextos reais, por meio de práticas e ações socioeducativas dentro e fora da escola.

\section{$\mathrm{O}$ ensino e a aprendizagem de inglês para crianças}

O ensino de LIC vem sendo discutido com frequência e, por consequência, surgem questões relacionadas ao desenvolvimento e à utilização de materiais didáticos, à formação de professores, à organização de salas de aula, aos modos de avaliar, às políticas linguísticas, entre outras (GARTON; COPLAND, 2019). Rocha (2010) explora a temática e aborda o ensino de LIC diante de todas as suas limitações e desafios, apontando que estes existem em função da falta de diretrizes específicas no Brasil, que não possui leis que garantam o ensino de inglês aos alunos da educação infantil e do primeiro ciclo do ensino fundamental. A autora aponta soluções a alguns dos problemas que os professores podem vivenciar em salas de aula de inglês com crianças pequenas, com base em evidências que apontam a necessidade de melhor preparação dos professores para a atuação no contexto de ensino de LIC, conforme mostram Tonelli, Ferreira e Belo-Cordeiro (2017).

Assim como Garton e Copland (2019), acreditamos que está aumentando a oferta do inglês como língua adicional nas séries iniciais na América Latina e no Brasil. A ausência de leis e diretrizes claras faz com que a proposta de pesquisas surja como a fonte ideal para o reconhecimento de ideias, materiais e abordagens que ofereçam suporte aos profissionais que se formam nos cursos de graduação e veem a área de ensino de LIC como um campo em que há espaço para exercerem a docência.

Concordamos com Rocha (2010) quando discorre sobre as implicações da globalização no mundo, que reforçam problemáticas como a da desigualdade, diante de uma população cada vez mais repleta de uma pluralidade linguística e cultural que poderia e deveria ser reforçada como identidade individual de cada aluno. Ainda, em acordo com a autora, reconhecemos o importante papel que exerce a Linguística Aplicada neste processo, porém, para que sejam superadas 
tais implicações como as das dificuldades de ensino e aprendizagem em função da desigualdade social, os professores precisam estar preparados para ensinarem a todos, auxiliando e mediando esse processo, permitindo aos alunos se reconhecerem no ambiente escolar para que, deste modo, se identifiquem como participantes ativos na sociedade e construam as suas histórias como seres humanos críticos e linguisticamente desenvolvidos.

Assim como Lopes (2012), acreditamos ser necessário estar atentos não somente ao desenvolvimento cognitivo e linguístico dos alunos, mas também aos aspectos afetivos e sociais para a aprendizagem (VYGOTSKY, 2001, 2003). Quando falamos do ensino de LIC com o diagnóstico de TEA, é necessário que identifiquemos a forma como o desenvolvimento linguístico pode exercer papel fundamental para as relações sociais dos indivíduos, que podem ter as suas possibilidades de interação ampliadas pela compreensão e a utilização da segunda língua.

\section{Ampliando horizontes}

Partindo dos pressupostos inerentes à lei da inclusão escolar, todos os alunos devem ter direitos iguais, o que torna parte da função dos professores e gestores escolares criarem um ambiente que proporcione condições de desenvolvimento a seus alunos, independente de limitações impostas por suas deficiências.
No caso de os alunos com o diagnóstico de TEA, embora há as limitações nas capacidades de interação e socialização impostas pelo transtorno, entendemos que a aprendizagem e o desenvolvimento estejam relacionados ao conceito de plasticidade cerebral (VYGOTSKY, 1991), considerando o cérebro como uma unidade mutável que se desenvolve e pode se regenerar de forma gradativa, possuindo capacidades cognitivas que são transformadas de acordo com os estímulos que recebem ao longo da vida (COSTA; SILVA; JACÓBSEN, 2019).

Relacionando o conceito de plasticidade cerebral à área do ensino de línguas, compreendemos que o desenvolvimento linguístico seja processual e que erros decorrentes de dificuldades de aprendizagem dos alunos não apontem para a impossibilidade de aprender, mas para marcas de que a aprendizagem está ocorrendo. Como é por meio da linguagem que estabelecemos nossas relações, ações e comunicações, os seres humanos necessitam do desenvolvimento de suas capacidades linguísticas para agirem socialmente.

Tratando do ensino a crianças com TEA, Santos et al. (2013) apontam que as atividades a serem aplicadas devem conter estímulos concretos, para facilitar a organização visual e preterir a interação estritamente verbal. Em adição, Sousa, Costa e Castro (2012) indicam a necessidade da proposição de atividades que proporcionem a aprendizagem por 
meio da ludicidade, já que é fundamental que as crianças se interessem pela metodologia de ensino para que aprendam e se desenvolvam de forma significativa.

Sem desconsiderar o aspecto desafiador, Rocha e Tonelli (2013b) indicam a importância do ensino de inglês a alunos com TEA, relacionando o desenvolvimento dos indivíduos a forma como a aprendizagem de uma língua estrangeira/adicional pode auxiliar no processo de aquisição de novas capacidades de interação social e, consequentemente, cognitivas. Ademais, Santos et al. (2013) afirmam que, mesmo considerando as limitações inerentes ao diagnóstico de TEA, é necessário não nos atermos às atividades que não apresentem desafios aos alunos, que somente exercitem as habilidades que já possuem.

Desta forma, apontamos que trabalhar as dificuldades de desenvolvimento linguístico advindas do diagnóstico de TEA por meio da língua inglesa pode ser uma alternativa para ensinar aos alunos, desde que busquemos atividades que estimulem e permitam a aprendizagem da criança junto aos outros alunos no contexto de inclusão, porém, compreendendo que há limitações que exigem a exploração de materiais que oportunizem ao aluno a experiência de aprendizagem adequada a sua individualidade.

A proposta de ensino de LIC, por meio de gêneros textuais usando a SD como dispositivo de organização, aparece como uma possibilidade para o desenvolvimento de atividades que contemplem as necessidades específicas de cada criança, diante da possibilidade de adaptação (DOLZ, 2009) e da utilização de recursos tecnológicos multimodais, transpassando barreiras e buscando superar limites. É necessário que os professores explorem materiais que aproximem o aluno com TEA dos temas abordados nas atividades, a fim de que haja a compreensão linguística dos estímulos apresentados no contexto e, desta forma, o aluno passe a se interessar pelo idioma.

O aumento nas possibilidades de exploração de conteúdo que se apresenta junto ao estudo de uma segunda língua traz novas possibilidades de trabalho da comunicação ao aluno, possibilitando que os professores busquem alternativas e variem ainda mais as atividades, com o objetivo de adequá-las às individualidades.

Além do cuidado com os materiais e as próprias atividades, é importante que os professores saibam enxergar e valorizar seus papéis em relação ao aluno e a sua inclusão em sala de aula. A criança com TEA tem no professor uma figura de referência e busca nele a compreensão para comportamentos padrão em sala de aula, identificação de rotina e de organização (SANTOS et al., 2013).

Reconhecendo a importância da construção social e da identidade das crianças, Rocha e Tonelli (2013a, p. 36) afirmam: 
O ensino de LI é de suma importância para o aprendizado e desenvolvimento do aluno autista, pois este implica não apenas na aprendizagem linguística, mas também na inserção deste aluno na sociedade globalizada.

Entendemos que a aprendizagem de uma língua estrangeira/adicional pode representar a oportunidade de conhecimento de novas culturas, o que colabora para o desenvolvimento de um senso de sociedade, além da compreensão de elementos relacionados à diversidade, o que pode facilitar a aproximação da criança com TEA e auxiliar no estabelecimento dos seus vínculos sociais.

\section{Métodos e análise das atividades}

Diante das análises de atividades por meio do estudo de caso (YIN, 1993; DÖRNYEI, 2006) proveniente das atividades realizadas por um aluno, este artigo está inserido no paradigma qualitativo-interpretativo de dados (DENZIN; LINCOLN, 2006; COHEN; MANION; MORRISON, 2010).

Para identificar como podem ser organizadas e adaptadas atividades que promovam, de fato, a aprendizagem de inglês de crianças com TEA, apresentaremos três atividades arroladas em uma SD e aplicadas ao aluno S1, incluído em uma turma de nível pré-5 em um centro de educação infantil de universidade pública localizado no norte do estado do
Paraná, onde o primeiro autor realizou seu estágio supervisionado obrigatório, sob orientação da segunda autora. As atividades foram criadas e selecionadas sob o critério de estarem inseridas nos módulos ${ }^{4}$ da SD e terem sido idealizadas como intervenções específicas para o ensino e a inclusão de S1, considerando suas limitações.

Ressaltamos que todas as atividades foram coproduzidas e analisadas pelos autores assegurando, assim, aspectos éticos de pesquisa. A esse respeito, esclarecemos que a pesquisa desenvolvida está inserida em projeto de pesquisa mais amplo sob título "Ensino de línguas adicionais para crianças com base em gêneros textuais organizado em torno do dispositivo sequência didática: proposições de adaptações", registrado na Pró-reitoria de Pesquisa da Universidade Estadual de Londrina (UEL) (número 12597) e aprovado pelo Comitê de Ética em Pesquisa envolvendo seres humanos na mesma universidade, sob número 33755020.3.0000.523.

Durante o processo de elaboração da $\mathrm{SD}$, consideramos o fato de que o diagnóstico de autismo em grau severo de S1 implicava em dificuldades para se comunicar e se relacionar com outras crianças da turma, afetando também a oralidade e a possibilidade de participação de atividades com autonomia e mediação reduzida. S1 também apresentava interesses restritos, dando preferência à realização 
de propostas que envolvessem estímulos visuais, organização de figuras e atividades em que pudesse apresentar respostas por meio de movimentos corporais.

Tomando por base Bronckart (2003) e o conceito de par mais experiente (VYGOTSKY, 1998), desenvolvemos atividades que promovessem interações e escolhas conjuntas, para favorecer a comunicação e as trocas de experiências entre as crianças. Com base no contexto de aplicação das atividades, o gênero textual selecionado para ser o norteador das atividades da SD foi história infantil (HI) (TONELLI, 2005) e a HI utilizada na apresentação da situação ${ }^{5}$ aos alunos foi The Very Hungry Caterpillar ${ }^{6}$ (CARLE, 1969). Na produção inicial ${ }^{7}$, os alunos deveriam organizar a história na ordem correta dos seus acontecimentos, de acordo com os elementos e personagens mencionados pelo professor, colando as figuras na ordem correta $\mathrm{e}$ reconhecendo o que fosse requisitado. A realização desta atividade tinha por objetivo diagnosticar os conhecimentos dos alunos e foi realizada em grupos de quatro crianças, sendo que cada uma realizava as etapas e respondia aos comandos individualmente. Durante a atividade, foi percebida a necessidade de intervenções para o desenvolvimento das CL de S1 e dos outros alunos, pois demonstraram dificuldades para o reconhecimento das partes da história e das personagens em inglês.
A primeira atividade de S1 que trazemos para a análise (Figura 1) teve por objetivo aproximar as crianças do conceito e do papel do personagem por meio da identificação da personagem principal da HI utilizada na apresentação da situação. Os alunos deveriam pintar somente a lagarta, repetindo oralmente o nome da personagem junto ao professor. $\mathrm{Na}$ atividade exposta por meio da Figura 1, a seguir, percebemos que $\mathrm{S} 1$ conseguiu identificar e pintar a personagem principal da HI, conforme requisitado no enunciado da atividade.

Figura 1 - Pinte a personagem da $\mathrm{HI}$

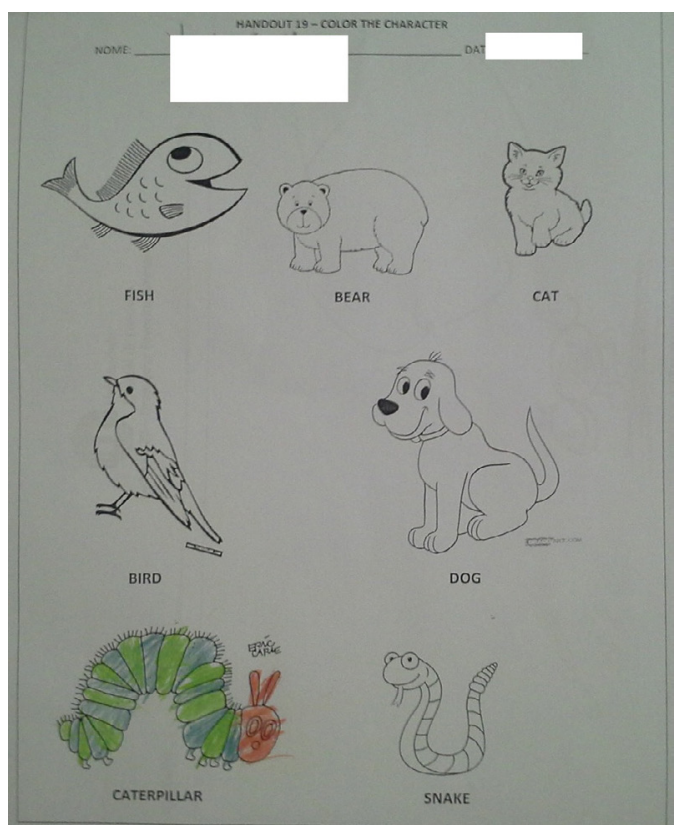

Fonte: os autores.

Tendo em vista o fato de que o aluno ainda não tinha a oralidade desenvolvida 
em função do TEA, foi solicitado a ele que apontasse para a personagem, enquanto o professor repetia o nome da lagartinha em inglês: caterpillar. $\mathrm{O}$ aluno participou ativamente da proposta, realizando a atividade conforme havia sido requisitado, assim como os seus colegas de turma.

A segunda análise é de uma atividade em que o mesmo aluno, S1, teve que escolher qual seria a personagem principal em sua própria HI, já que a produção final da SD consistia na elaboração e contação de uma história. Para que S1 pudesse selecionar o animal, trouxemos imagens com várias opções e pedimos que ele escolhesse, dentre todas elas, qual era o seu animal favorito. Durante a mediação, foi necessário chamar a atenção de S1 para as figuras algumas vezes, a fim de concentrá-lo na proposta; porém, após certo tempo, $\mathrm{S} 1$ escolheu a figura do cachorro. Na Figura 2, apresentamos o desenho realizado por ele, no qual representou o animal escolhido.

Figura 2 - Desenhe seu animal favorito

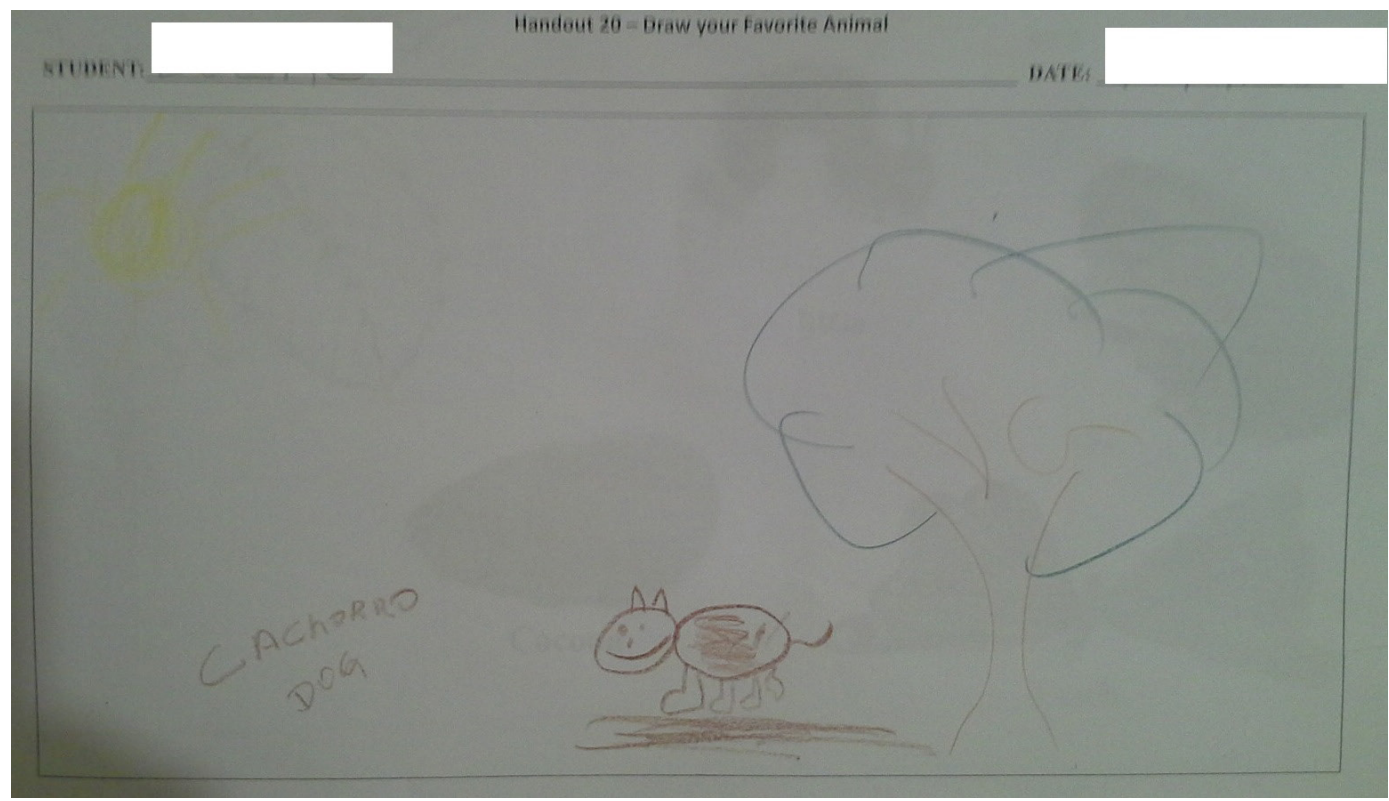

Fonte: os autores.

Após a realização desta atividade, a escolha de todos os alunos da sala foi compartilhada por meio da apresentação do desenho à frente da classe e a explicação de qual havia sido o animal escolhido. Com o auxílio do professor, $\mathrm{S} 1$ foi à frente e mostrou o seu desenho, apontando para o cachorro, para reforçar a escolha da personagem principal da HI. 
A última atividade (Figura 3) que trazemos teve por objetivo desenvolver as capacidades linguístico-discursivas e as capacidades de ação do aluno, já que alia estudo referente às partes da história e ao vocabulário utilizado. Na referida atividade, foi solicitado a $\mathrm{S} 1$ que relacionasse o conteúdo abordado na história The
Very Hungry Caterpillar e em sua própria HI, observando desenhos da lagartinha como é no início e das comidas que ela comeu no meio do enredo, e desenhando a sua própria versão da história, com o cachorro como personagem principal, representando também um acontecimento que ocorreria no meio da HI.

Figura 3 - O que o cachorro come

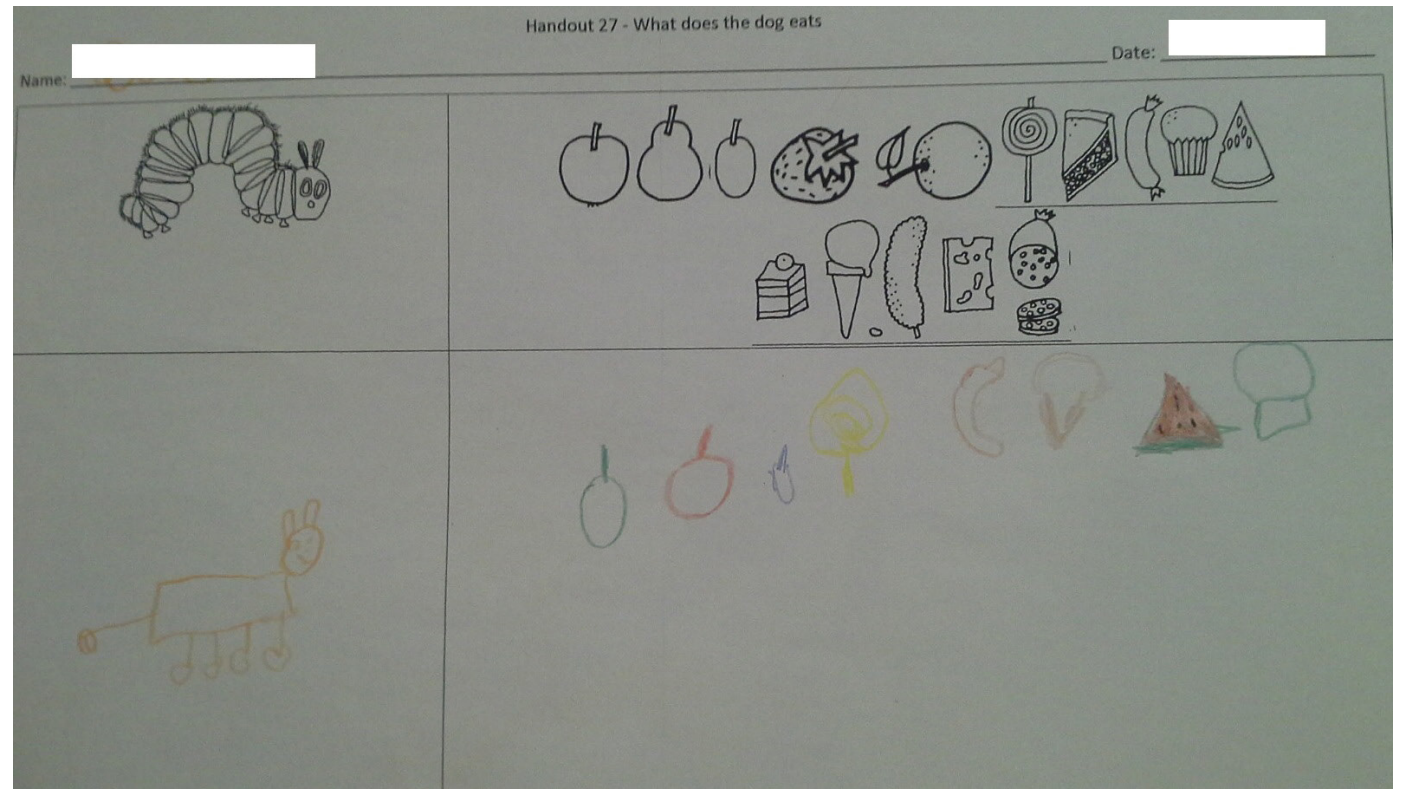

Fonte: os autores.

Nesta atividade podemos observar que o aluno fez a relação entre algumas das comidas que a lagartinha comeu e também as desenhou. Porém, ele não ilustrou todas as comidas, demonstrando a capacidade de escolher entre as frutas, doces e salgados, quais, dentre esses, ele gostaria de incluir em sua história, para representarem um dos acontecimentos que fariam parte do enredo no meio da HI. Da mesma forma que a anterior, esta atividade foi apresentada em frente à sala, processo do qual o professor fez parte, mediando e auxiliando $\mathrm{S} 1$ para que socializasse seu desenho ao restante da turma. 
Após o desenvolvimento das atividades, o aluno conseguiu, como produção final da SD, com mediação do professor, criar a sua própria HI, optando pelo cachorro como personagem principal da história, escolhendo as comidas que fariam parte do enredo, quando o cachorro fica forte e grande, e incluindo um final, em que o cachorro ficou velhinho e teve filhotinhos.

\section{Conclusão}

Apesar de termos apresentado neste artigo as leis e diretrizes que colocam a inclusão e reafirmam o direito de educação a todos no Brasil na atualidade, a falta de recursos e capacitação de profissionais faz com que, muitas vezes, a inclusão, na prática, não ocorra. $\mathrm{Na}$ escrita deste texto, tivemos como objetivo reunir evidências que pudessem indicar que, no caso apresentado, não somente é possível ensinar inglês a crianças com TEA, mas também que a aprendizagem da língua adicional pode promover o desenvolvimento linguístico dos alunos.

A proposta da escola como um ambiente acolhedor, que favoreça o desenvolvimento do aluno como um ser que possui a sua identidade e papel na sociedade, só é cumprida e os objetivos só são alcançados, se as oportunidades são apresentadas a todos os alunos, respeitando as individualidades de cada um, as especificidades e necessidades educacionais especiais. No caso do ensino de LIC a alunos com TEA, nota-se que a adaptação de materiais é essencial para que o ensino e a aprendizagem ocorram de forma efetiva. Assim, propostas que não sejam estritamente verbais, mas que envolvam estímulos visuais e concretos em atividades lúdicas fazem-se necessárias. Além disto, importa ressaltar a importância da figura do professor como mediador em sala de aula, assumindo, assim, um papel essencial no processo de criação da identidade da criança como um aluno que não somente faz parte do contexto escolar, mas que dele participa ativamente a despeito de suas limitações.

Consideramos que, quando as aulas são planejadas mantendo em vista as questões discutidas neste artigo, tendo em conta as limitações em que implicam o diagnóstico de TEA e as individualidades de cada aluno, o ensino de LIC pode favorecer o desenvolvimento linguístico de crianças acometidas pelo autismo, ampliando os horizontes do aluno e possibilitando a superação de desafios relacionados às dificuldades na comunicação e interação próprios ao transtorno. Reconhecendo os desafios que envolvem o ensino da LIC a alunos com diagnóstico de TEA, propomos privilegiar as possibilidades que tal prática pode proporcionar aos alunos, abrindo espaço para novas discussões e pesquisas que reforcem a importância da criação de espaços para 
o autoconhecimento e o estabelecimento de vínculos sociais por meio do desenvolvimento linguístico. Entendemos que a aprendizagem do idioma representa uma conquista valiosa não só para os alunos, mas também aos professores que atuam no contexto de LIC. Assumimos que existam dificuldades impostas pelo TEA, mas afirmamos que estas não impedem a interação e a aprendizagem.

Por meio deste artigo, esperamos colaborar para que outros professores e pesquisadores se dediquem a pensar atividades, adaptar materiais e ensinar a alunos com deficiência em contexto de inclusão, motivando-os a realizarem seus trabalhos para compreender que é possível atingir seus objetivos relacionados ao ensino e à aprendizagem e que é importante que busquem identificar as maneiras como as atividades que proporcionam e as abordagens de ensino podem e devem ser significativas para 0 desenvolvimento de seus alunos.

A expectativa é que haja um movimento crescente de pesquisas com propostas de reflexão que possibilitem aos professores refletirem a respeito de seus papéis como mediadores do conhecimento das disciplinas que lecionam em sala de aula, reforçando a importância de suas ações para a construção de conhecimento e identidade de cada uma de suas crianças, sejam eles alunos com deficiência, ou alunos regulares ${ }^{8}$.

\section{Expanding horizons: teaching English to children with autism spectrum disorder}

\section{Abstract}

When it comes to teaching English to children, the education scenario nowadays is presented as opened to new research proposals that reinforce the importance of inclusion in scholar context. In this paper we aim to discuss, through qualitative-interpretative analysis, the role of English learning to the linguistic development of children with Autistic Spectrum Disorder, discussing the contribution of the English language to the process of overcoming the challenges that may arise from the diagnosis. The data were generated through activities that are part of a didactic sequence developed and applied in a supervised internship context, to a level 5 group of students, including an autistic child. The results point out that, whether didactic material and approach adaptations are made, teaching English to children with autistic spectrum disorder can favor their linguistic development, in addition to enabling social engagement, characterizing, in fact, inclusion.

Keywords: Teaching English for children. Autistic spectrum disorder. Scholar inclusion. Linguistic development.

\section{Notas}

1 Dispositivo didático para a organização de atividades visando o ensino de línguas e o desenvolvimento das capacidades de linguagem (DOLZ; NOVERRAZ; SCHNEUWLY, 2004). 
2 As capacidades de linguagem são as que devem ser dominadas para que indivíduos sejam capazes de compreender e utilizar gêneros textuais orais e/ou escritos. São elas: capacidades de ação, capacidades discursivas e capacidades linguístico-discursivas (DOLZ; PAZQUIER; BRONCKART, 1993). Tais capacidades foram expandidas por Cristovão e Stutz (2011), com a proposição da inclusão das capacidades de significação.

3 Diagnostic and statistical manual of mental disorders, em inglês.

4 As atividades das SD são arroladas em módulos, sendo que cada um possui uma temática e um objetivo condizente com o desenvolvimento das CL (DOLZ; NOVERRAZ; SCHNEUWLY, 2004).

5 Etapa da SD em que o gênero é apresentado aos alunos e é explicada a proposta do projeto de classe (DOLZ; NOVERRAZ; SCHNEUWLY, 2004).

$6 \quad$ Alagarta muito faminta, em língua portuguesa.

7 Nesta etapa da SD, o professor aplica uma atividade diagnóstica aos alunos, a fim de compreender o conhecimento prévio que possuem (ou não) em relação ao gênero e adaptar as atividades dos módulos (DOLZ; NOVERRAZ; SCHNEUWLY, 2004).

${ }^{8}$ Agradecemos a Profa. Dra. Betânia Passos Medrado, docente na Universidade Federal de Pernambuco, pela leitura crítica e sugestões para 0 artigo.

\section{Referências}

AMERICAN PSYCHIATRY ASSOCIATION. Diagnostic and Statistical Manual of Mental disorders - DSM-5. 5. ed. Washington: American Psychiatric Association, 2013.

BARROS, A. B.; SILVA, S. M. M.; COSTA, M. P. R. Dificuldades no processo de inclusão escolar: percepções de professores e alunos com deficiência visual das escolas públicas. Boletim - Academia Paulista de Psicologia, v. 35, p. 23, 2015.

BRASIL. Base Nacional Comum Curricular. Educação é a Base. Brasília, DF: Ministério da Educação, 2017. Disponível em: 568 http:// basenacionalcomum.mec.gov.br/images/
BNCC_publicacao.pdf. Acesso em: 02 jun. 2020.

BRASIL. Lei $\mathrm{n}^{\circ} 12.764$, de 27 de dezembro de 2012. Dispõe sobre a política nacional de proteção dos direitos das pessoas com transtorno do espectro autista. Disponível em: http://www.planalto.gov.br/ccivil_03/_ ato2011-2014/2012/lei/l12764.htm. Acesso em: 13 fev. 2016 .

BRASIL. Declaração de Salamanca: sobre princípios, políticas e práticas na área das necessidades educativas especiais. 1997. Disponível em: http://portal.mec.gov.br/seesp/arquivos/pdf/salamanca.pdf. Acesso em: 29 jun. 2015.

BRASIL. Ministério de Educação e Cultura. Lei $n^{\circ}$ 9.394, de 20 de dezembro de 1996 . Estabelece as diretrizes e bases da Educação Nacional. Brasília, DF: MEC, 1996.

BRASIL. Lei n⿳ํㅜㄹ.146, de 6 de julho de 2015 . Institui a Lei Brasileira de Inclusão da Pessoa com Deficiência (Estatuto da Pessoa com Deficiência). Disponível em: http://www.planalto.gov.br/ccivil_03/_ato2015-2018/2015/ lei/113146.htm. Acesso em: 04 jun. 2020.

BRASIL. Constituição (1988). Constituição da República Federativa do Brasil. Brasília, DF, 1988.

BRONCKART, J. P. Atividade de linguagem, textos e discurso: por um interacionismo sócio-discursivo. Tradução de Anna Raquel Machado e Péricles Cunha. São Paulo: EDUC, 2003.

CARNEIRO, R. U. C. Educação Inclusiva na Educação Infantil. Práxis Educacional, v. 8, p. 81-95, 2012.

CARLE, E. The Very Hungry Caterpillar. United States: Putnam/Philomel, 1969.

COSTA, A. R.; SILVA, P. L. O. da; JACÓBSEN, R. T. Plasticidade cerebral: conceito(s), contribuições ao avanço científico e estudos brasileiros na área de Letras. Entrepalavras, Fortaleza, v. 9, n. 3, p. 457-476, set./dez. 2019. 
COUDRY, M. I. H.; FREIRE, F. M. P. $O$ trabalho do cérebro e da linguagem: a vida e a sala de aula. Campinas: CEFIEL, 2005.

CRISTOVÃO, V. L. L.; STUTZ, L. Sequências didáticas: semelhanças e especificidades no contexto francófono como L1 e no contexto brasileiro como LE. In: SZUNDY, P. T. C. et al. (org.). Linguistica Aplicada e Sociedade: ensino e aprendizagem de línguas no contexto brasileiro. Campinas: Pontes Editores, 2011. p. 17-40.

COHEN, L.; MANION, L.; MORRISON, K. Research methods in education. 6. ed. London: Routledge, 2010.

DENZIN, N.; LINCOLN, Y. O Planejamento da pesquisa qualitativa: teorias e abordagens. Porto Alegre: ArtMed, 2006.

DOLZ, J.; PASQUIER, A.; BRONCKART, J. P. L'acquisition des discours: émergence d'une compétence ou apprentissage de capacités langagières? Études de Linguistique Appliquée, n. 102, p. 23-37, 1993.

DOLZ, J.; NOVERRAZ, M.; SCHNEUWLY, B. Sequências didáticas para o oral e a escrita: apresentação de um procedimento. In: SCHNEUWLY, B.; DOLZ, J. Gêneros orais e escritos na escola. Trad. Roxane Rojo e Glaís Sales Cordeiro. Campinas: Mercado de Letras, 2004. p. 95-128.

DOLZ, J. Os cinco grandes desafios da formação docente de línguas. 2009. Disponível em: http://www.ucs.br/ucs/tplSiget/extensao/ agenda/eventos/vsiget/portugues/Download\%20\%20das\%20palestras/Mesa-redonda_13.08_Joaquim\%20Dolz.pdf. Acesso em: 06 out. 2020.

DÖRNYEI, Z. Research methods in applied linguistics: quantitative, qualitative and mixed methodologies. Oxford: Oxford University Press, 2006.

GARTON, S.; COPLAND, F. The Routledge Handbook of Teaching English to Young Learners. New York: Routledge, 2019.
LEMOS, E. L. M. D.; NUNES, L. L.; SALOMÃO, N. M. R. Transtorno do espectro autista e interações escolares: sala de aula e pátio. Revista Brasileira de Educação Especial, Bauru, v. 26, n. 1, jan./mar. 2020.

LOPES, L. M. Ludicidade: uma alternativa para a educação inclusiva no ensino regular. 2012. 58 f. Trabalho de Conclusão de Curso (Pós-graduação em Educação: Métodos e Técnicas de Ensino) - Universidade Tecnológica Federal do Paraná, Medianeira, 2012.

MEDRADO, B. P.; CELANI, M. A. A. A Lei Brasileira de Inclusão: as antigas e novas demandas para a formação de professores de línguas. In: MATEUS, Elaine; TONELLI, Juliana (org.). Diálogos (im)pertinentes entre formação de professores e aprendizagem de línguas. São Paulo: Blucher Open Access, 2017. v. 1. p. 203-220.

PENNINGTON, B. F. 1946 -Diagnósticos de distúrbios de aprendizagem: um referencial neuropsicológico. São Paulo: Pioneira, 1997.

ROCHA, C. H. Propostas para o inglês no ensino fundamental I público: plurilinguismo, transculturalidade e multiletramentos. Tese (Doutorado em Linguística Aplicada) - Instituto de Estudos da Linguagem, Universidade Estadual de Campinas, Campinas, 2010.

ROCHA, E. P.; TONELLI, J. R. A. A Síndrome de Asperger e o ensino de língua inglesa: possibilidades e desafios. Revista $X / U F P R$, v. 1, n. 1, p. 38-48, 2013a.

ROCHA, E. P.; TONELLI, J. R. A. O autista na sala de aula de Língua Inglesa: um dilema, ou um mundo de oportunidades? Revista Eletrônica Pro Docência / UEL, v. 1, n. 3, jan./ jun. 2013b. Disponível em: http://www.uel. br/revistas/prodocenciafope. Acesso em: 08 out. 2020.

ROCHA, E. P. Possibilidades e desafios na formação de professores de língua inglesa a indivíduos com a Síndrome de Asperger. 2016. 142 f. Dissertação (Mestrado em Estudos da Linguagem) - Universidade Estadual de Londrina, Londrina, 2016. 
SANCHES, I.; TEODORO, A. Da integração à inclusão escolar: cruzando perspectivas e conceitos. Revista Lusófona de Educação, v. 8, p. 63-83, 2006.

SANTOS, A.; BISPO, M.; PINHEIRO, N. S.; SANTANA, T. O. Metodologias de ensino para crianças autistas: superando limitações em busca da inclusão. Anais Fiped V, v. 1, n. 2, 2013. Disponível em: http://www.editorarealize.com.br/revistas/fiped/trabalhos/Trabalho_Comunicacao_oral_idinscrito_1695_ee8a90ab371b8e7be05bf467184f1ded.pdf. Acesso em: 09 out. 2020.

SANTOS, L. I. S. Professores de língua inglesa para crianças: interface entre formação inicial e continuada, experiência e fazer pedagógico. Revista Brasileira de Linguística Aplicada, v. 11, p. 223-246, 2011.

SILVEIRA, S. N.; SANTOS, A. J.; SILVA, M. K. A Formação do Professor de Língua Inglesa e o Processo de Inclusão da Criança com Transtorno do Espectro Autista - TEA na Sala de Aula. In: SEMANA INTERNACIONAL DE PEDAGOGIA, 4; SEMINÁRIO LUSO-BRASILEIRO DE EDUCAÇÃO INFANTIL, 1; 21 a 25 de novembro de 2015. Anais [...]. Universidade Federal de Alagoas, 2015.

SOUSA, F. R. M.; COSTA, E. A. B.; CASTRO, T. H. C. WorldTour: Software para Suporte no Ensino de Crianças Autistas. In: SIMPÓSIO BRASILEIRO DE INFORMÁTICA NA EDUCAÇÃO (SBIE), 2012. Anais [...]. Rio de Janeiro: Sociedade Brasileira de Computação, 2012. p. 1-10. Disponível em: http:// www.br-ie.org/pub/index.php/sbie/article/ view/1806. Acesso em: 04 out. 2020.

TONELLI, J. A. R.; CRISTOVÃO, V. L. L. O papel dos cursos de Letras na formação de professores de inglês para crianças. Calidoscópio (Unisinos), v. 8, p. 65-76, 2010.

TONELLI, J. R. A. Histórias infantis no ensino da língua inglesa para crianças. 2005. Dissertação (Mestrado em Estudos da Linguagem) - Universidade Estadual de Londrina, Londrina, 2005.
TONELLI, J. R. A.; FERREIRA, O. H. S. Adaptação de sequência didática para o ensino de inglês a uma criança com transtorno do espectro do autismo. In: CELANI, Maria Antonieta Alba; MEDRADO, Betânia Passos (org.). Diálogos sobre inclusão: das políticas às práticas na formação de professores de línguas estrangeiras. Campinas: Pontes, 2017. v. 1. p. 201-228.

TONELLI, J. R. A.; FERREIRA, O. H. S.; BELO-CORDEIRO, A. E. Remendo novo em vestido velho: uma reflexão sobre os cursos de letras-inglês. Revista Educação, Linguagem e Literatura, v. 9, n. 1, 2017.

TUTIDA, A. F. Ensino de língua inglesa para crianças: questões sobre formação de professores e os saberes da prática. 2016. Dissertação (Mestrado em Estudos da Linguagem) - Programa de Pós-Graduação em Estudos da Linguagem, Universidade Estadual de Londrina, Londrina, 2016.

VITALIANO, C. R. Educação inclusiva e as reconstruções necessárias no processo de formação de professores. In: LIMA, Angela Maria de Sousa et al. (org.). Inclusão: debates em diferentes contextos. Londrina: Universidade Estadual de Londrina, 2013. v. 1. p. 15-25.

VYGOTSKY, L. S. A formação social da mente. 6. ed. São Paulo: Martins Fontes, 1998.

VYGOTSKY, L. S. Pensamento e linguagem. 3. ed. São Paulo: Martins Fontes, 1991.

VYGOTSKY, L. S. Psicologia pedagógica. São Paulo: Martins Fontes, 2001.

VYGOTSKY, L. S. Ciclo da Aprendizagem. Revista Escola, ed. 160, Fundação Victor Civita, São Paulo, 2003.

YIN, R. Applications of case study research. Beverly Hills, CA: Sage Publishing, 1993. 